\title{
Attitudes toward birth spacing among women in Eastern Uganda
}

\author{
Owen Albin ${ }^{\mathrm{a}, *}$, Nicholas Rademacher ${ }^{\mathrm{a}}$, Preeti Malani ${ }^{\mathrm{b}}$, Levert Wafula ${ }^{\mathrm{c}}$, Vanessa K. Dalton ${ }^{\mathrm{d}}$ \\ a University of Michigan Medical School, Ann Arbor, MI, USA \\ ${ }^{\mathrm{b}}$ Department of Internal Medicine, University of Michigan Medical School, Ann Arbor, MI, USA \\ c Bushikori Christian Center, Mbale, Uganda \\ d Department of Obstetrics and Gynecology, University of Michigan Medical School, Ann Arbor, MI, USA
}

\section{A R T I C L E I N F O}

Article history:

Received 31 July 2012

Received in revised form 2 September 2012

Accepted 23 October 2012

Keywords:

Birth interval

Birth spacing

Maternal mortality

Uganda

Birth intervals of less than 2 years are linked to adverse health outcomes for both infants and mothers [1]. Uganda has a total fertility rate of 6.7 children per woman, according to the 2006 Uganda Demographic and Health Survey (DHS) [2]. In the same survey, 31\% of women with 1 child in Uganda expressed a desire to have another child within 2 years [2]. Understanding the reasons for suboptimal birth spacing is necessary to improve infant and maternal health.

After obtaining Institutional Review Board approval, a convenience sample was collected of consecutive women (aged 18-49 years) presenting for primary care to the Bushikori Christian Centre Health Clinic in Mbale, Uganda, from June 7-25, 2010. A total of 183 women consented to participate in the study and were surveyed to assess attitudes toward and knowledge of birth spacing by measuring their level of agreement with 10 birth interval-relevant statements. Respondents had a mean age of 27.7 years and an average of 2.8 living children. Results of the survey are shown in Table 1.

Only 40 (22\%) respondents cited a healthcare provider (HCP) as their primary source of birth spacing information, compared with 143 (78\%) who cited their spouse for the same purpose. Respondents relying on an HCP for information had higher completed educational levels and lower mean parity than those who relied on their spouse for birth spacing information. Only 28 (15\%) women agreed that they had a larger say than their spouse over when to have their next child. Only 40 (22\%) women reported speaking to a health professional about birth spacing following the birth of their first child.

According to the 2006 Uganda DHS, unmet need for family planning, defined broadly as the expressed desire of a woman to space or limit her pregnancies combined with a lack of any traditional or modern contraceptive plan, totals $40.6 \%$ of the married female population [2]. The results of the present study suggest discordance between spouses regarding family planning decision making, a finding of potential importance given that the absence of couple negotiation

\footnotetext{
* Corresponding author at: c/o Vanessa K. Dalton, 1500 E. Medical Center Dr., L4000 Women's Hospital, Ann Arbor, MI 48109, USA. Tel.: +1 734647 9726; fax: +1 734 6479727.

E-mail address: oalbin@umich.edu (0. Albin).
}

Table 1

Birth spacing attitudes and knowledge among women in Eastern Uganda $(n=183)$.

\begin{tabular}{|c|c|}
\hline Birth spacing attitudes and knowledge & No. (\%) \\
\hline \multicolumn{2}{|l|}{ Issues of knowledge } \\
\hline Correctly identified best birth spacing interval & $160(87.4)$ \\
\hline $\begin{array}{l}\text { Agreed with "it is safe to give birth to a child within } 2 \text { years after the } \\
\text { birth of my last child" }\end{array}$ & $161(87.9)$ \\
\hline $\begin{array}{l}\text { Agreed with "using birth control is a safe way to plan the timing of } \\
\text { my next pregnancy" }\end{array}$ & $174(95.1)$ \\
\hline $\begin{array}{l}\text { Agreed with "a child born exactly } 1 \text { year after his or her sibling will } \\
\text { be just as healthy as his or her sibling" }\end{array}$ & $7(3.8)$ \\
\hline $\begin{array}{l}\text { Agreed with "waiting less than } 1 \text { year between pregnancies is unsafe } \\
\text { for mothers" }\end{array}$ & $163(89.1)$ \\
\hline \multicolumn{2}{|l|}{ Attitudes and beliefs } \\
\hline $\begin{array}{l}\text { Cited a healthcare professional as their primary source of birth } \\
\text { spacing information }\end{array}$ & $40(21.9)$ \\
\hline Cited their spouse as their primary source of birth spacing information & $143(78.1)$ \\
\hline $\begin{array}{l}\text { Agreed with "waiting too long between having children will make } \\
\text { my friends and/or relatives look at me in a negative way" }\end{array}$ & $179(97.8)$ \\
\hline $\begin{array}{l}\text { Agreed with "I have a larger say than my spouse over when to have } \\
\text { our next child" }\end{array}$ & $28(15.3)$ \\
\hline Agreed with "Having a large family is important to me" & $1(0.5)$ \\
\hline \multicolumn{2}{|l|}{ Issues of access/system } \\
\hline $\begin{array}{l}\text { Agreed with "after the birth of my first child, a health professional } \\
\text { and I discussed when it would be best to have another child" }\end{array}$ & $40(21.9)$ \\
\hline $\begin{array}{l}\text { Agreed with "I don't have access to materials that would help me } \\
\text { plan when to have our next child" }\end{array}$ & $15(8.2)$ \\
\hline
\end{tabular}

in Uganda has been correlated with a higher prevalence of unmet need for family planning [3]. The results also demonstrate a lack of health provider involvement in postpartum family planning, consistent with previous studies in this region [4]. Although limited by sample size and convenience sampling, these results suggest that effective interventions to combat suboptimal birth spacing will need to be multifaceted, addressing spousal involvement in family planning and emphasizing family planning in postpartum care.

\section{Conflict of interest}

The authors have no conflicts of interest to disclose.

\section{References}

[1] Conde-Agudelo A, Rosas-Bermúdez A, Kafury-Goeta AC. Birth spacing and risk of adverse perinatal outcomes: a meta-analysis. JAMA 2006;295(15):1809-23.

[2] Uganda Bureau of Statistics, Macro International Inc. Uganda Demographic and Health Survey 2006. http://www.measuredhs.com/pubs/pdf/FR194/FR194.pdf. [Published August 2007].

[3] Wolff B, Blanc AK, Ssekamatte-Ssebuliba J. The role of couple negotiation in unmet need for contraception and the decision to stop childbearing in Uganda. Stud Fam Plann 2000;31(2):124-37.

[4] Bradley J. Missed opportunities: postpartum family planning in Kenya. AVSC News 1993;31(3):7. 